\title{
ANALYSIS PATTERNS FOR MILITARY ORGANIZATIONS Elena DUMITRU
}

\author{
“Nicolae Bălcescu” Land Forces Academy, Sibiu, clencielena@yahoo.ro
}

\begin{abstract}
The need to study and the use of science and practice of knowledge management is a necessity for the military system as a major subsystem (in economic terms) of any social system. In the type of knowledge that is necessary for the state to support national interests, knowledge transformation that starts from the premises of the environment in which they operate and on which it is called upon to be decided. Knowledge is the ability to understand the present reality based on information, perceptions and evaluations, and the ability to support actions in order to shape future realities.
\end{abstract}

Keywords: Knowledge, data, intellectual capital, strategic knowledge management

\section{Introduction}

Knowledge management $(\mathrm{KM})$ is the process of enabling knowledge flow to enhance shared understanding, learning and decision making. Knowledge flow refers to the ease of movement of knowledge within and among organizations. Knowledge must flow in order to be useful. The purpose of knowledge management is to create a shared understanding through the alignment of people, processes, and tools within the organizational structure and culture in order to increase collaboration and interaction between leaders and subordinates. This results in better decisions and enables improved flexibility, adaptability, integration, and synchronization to achieve a position of relative advantage [1]. Sound KM practices enhance:

- Collaboration among personnel at different places;

- Rapid knowledge transfer between units and individuals;

- Reach-back capability to army school, centres of excellence, and other resources;
- Leader and soldier agility and adaptability during operations;

- Doctrine development;

- An organization's ability to capture lessons learned throughout each force pool of the army force generation cycle;

- Effective and efficient use of knowledge in conducting operations, and supporting organizational learning are essential functions of KM.

$\mathrm{KM}$ is more than improved information technology and communications systems. It supports all elements of the operations and decision making processes. Knowledge managers integrate the KM process and its activities into all the processes and information systems of an organization to ensure that knowledge is shared. This integration helps to enable the flow of knowledge that resides in individuals and small elements across the organizational learning, innovation, and performance.

Every soldier must understand and practice KM. It enables the army and its subordinate commands at every level to be learning organizations. 
Commanders are responsible for ensuring that effective $\mathrm{KM}$ practices are taking place within the unit or organization. Through the KM process, knowledge managers assist commanders and other members of the organization in following sound $\mathrm{KM}$ practices and using information management tools that the unit command structure establishes. They assist the organization in managing the knowledge environment.

Knowledge is information that has been analysed to provide meaning or value or evaluated as to show the implications for the operation. It is also comprehension gained through study, experience, practice, and human interaction that provides the basis for expertise and skilled judgement. Individuals gain knowledge when they place information in a context based on what they already know, available factual information, as well as on their judgement and experience.

\section{Assessment}

The steps of the knowledge management process are sequential, normally beginning with assessment, but knowledge managers may revisit the steps as needed.

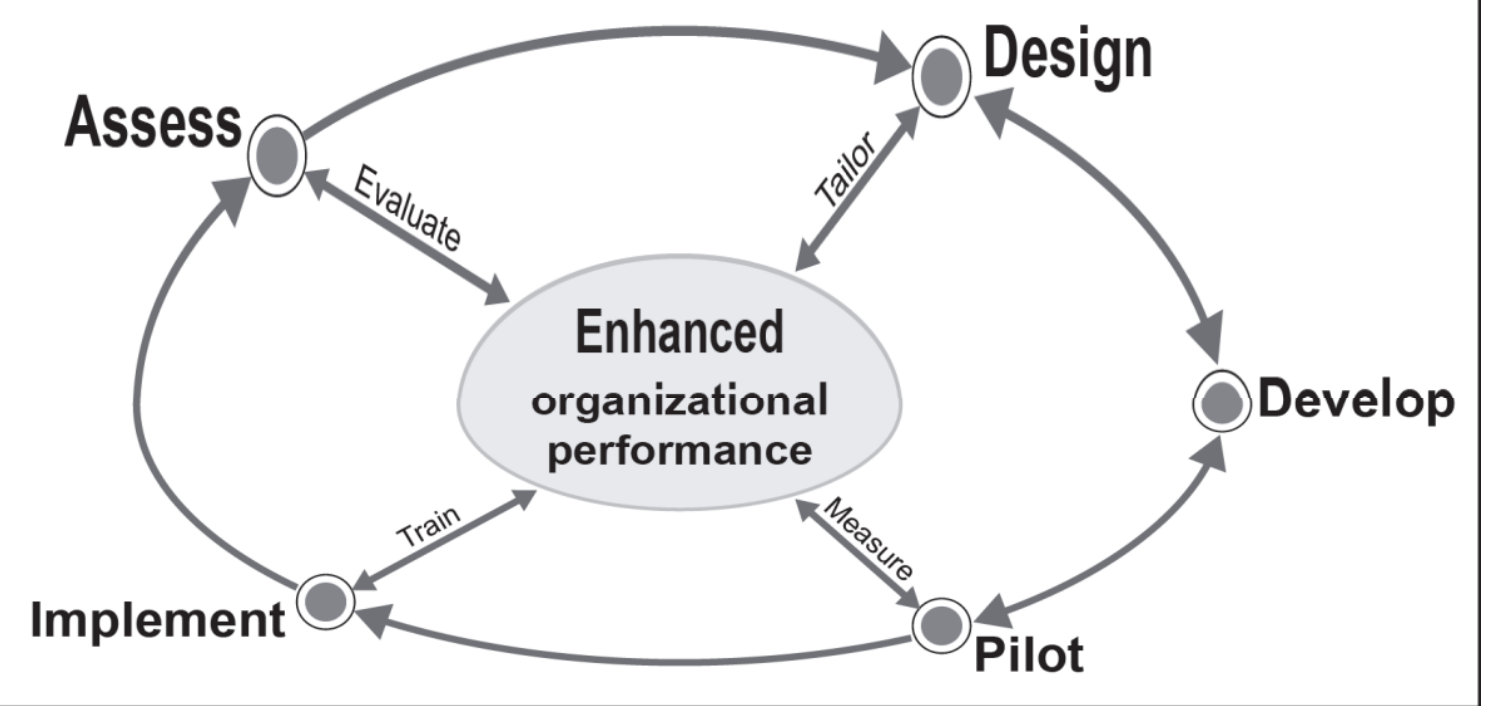

Figure 1: The knowledge management process

Each step normally includes subordinate activities that are not necessarily limited to a given step. Examples of subordinate activities are discussed under the step with which they are commonly associated. The knowledge management section considers and selects the most appropriate activities for the unit. The knowledge management section can modify the process according to the need of the unit.

As a step of the operations process, assessment is continuously monitoring and evaluating the current situation and the progress of an operation. In the context of the knowledge management process, assessment means analysing the unit knowledge needs. It results in establishing knowledge management objectives for the unit.

Assessment precedes all the other steps. This step begins with determining what information leaders need to make decisions, and how the unit provides this information for those leaders. It identifies gaps in the process, and as it establishes objectives, it begins to consider possible solutions to address the gaps. As the solutions are implemented, they are assessed to evaluate their effectiveness and to recommend new solutions or improvements.

Assessment is continuous because it includes monitoring the current situation 
and progress towards accomplishing those objectives. Monitoring begins with evaluating the foundations of a unit - that is, how the unit manages time and information, and what is considered critical for its leaders to make decisions. Unit performance drives assessment, as knowledge managers assist the unit in identifying the difference between what its members know and what they must know to accomplish the mission. The information the unit needs will drive the assessment of how that information should be provided, disseminated, displayed, and processed to help foster knowledge creation.

Contributing to the assessment step, the $\mathrm{KM}$ officer may consider conducting interviews with leaders and personnel at every level within the organization. Having the perspectives of many members of unit or organization will help in defining knowledge-based solutions that can then be staffed and more likely accepted. Depending upon the situation and the rapport the interviewer is able to establish, interviews may be structured, semistructured, or unstructured in nature. Interviews help identify shortfalls in knowledge management proficiency that must be addressed, the maturity of existing knowledge management practices in the unit, and knowledge management gaps. Analysis of the knowledge of the unit needs determines if the performance shortfalls require additional training, materiel, or knowledge solutions. Aligning solutions to shortfalls is the key to solving the problem. If knowledge is seen as deficient, the $\mathrm{KM}$ section recommends knowledge-based solutions.

\section{Designing}

In the context of the knowledge management process, designing is identifying tailored $\mathrm{KM}$ products or services that effectively and efficiently answer information requirements and meet the objectives established in the assessment step. The KM products or services could be refinements of an existing process or a new solution identified after the assessment. For example, if soldiers waste time finding documents or expertise related to a specific job, the unit needs to determine where to find an expert or a reference. The solution may be to design a community of practice for soldiers with similar experiences and expertise to interact with others performing similar duties. Another solution may be to create a knowledge centre with a document library and a help desk. During the designing step, knowledge managers must determine which knowledge strategy would best meet the unit needs. A key consideration is whether the unit knowledge shortfalls lie more in the transfer of knowledge or whether knowledge creation is the requirement. The knowledge requirements strategy gives priority to one or the other. A strategy that focuses on developing social networks supports organizing, applying, and transferring explicit knowledge. A strategy that focuses on developing social networks is wellsuited to transferring or creating tacit knowledge.

Designing activities may include, but are not limited to designing knowledge networks. A knowledge network is social and interpersonal as well as technical. This network type helps units to rapidly share tactics, techniques, and procedures; operational observations, insights, and lessons; and validated, explicit knowledge products. The knowledge network architecture uses the technical architecture established by the signal staff section.

\section{Development}

Development is the step that actually builds the solution derived from the assessment and design steps. First, knowledge managers and the staff collaborate to establish the social framework for the virtual communities designed in the preceding step. Knowledge management representatives (KMRs) provide insight and advice on the social frameworks best suited to the organization. Once the social frameworks are established for the virtual communities, signal staff section personnel, usually portal administrators or designers, 
assist in connecting them to the technical network. The KM section works with the unit on both aspects of this step.

\section{Piloting}

Piloting is deploying the KM solution and testing it with the unit to validate it. This aspect is an incremental test of a modification to an existing process or procedure. Important considerations of the pilot step include communicating the proposed KM solution to the commander and staff and ensuring acceptance or discussing alternatives as needed. The KM section must be prepared to train and coach the unit personnel as needed in order to successfully deploy and test the solution. Key activities of the pilot step are collaborative assistance and team-peer assistance.

\section{Implementation}

Implementation is executing the validated KM solution and integrating it into the unit information systems that support the mission command components and operations within any phase of the operations process. Training and coaching personnel on their specific roles and tasks continues as needed. Knowledge managers monitor the initial implementation of the KM solution and make any adjustments needed. Once the KM solution is fully implemented and integrated into the operations process, knowledge managers continue to monitor and assess the results.

The KM solution, when implemented, enables the unit to become a "learning organization" - able to effectively and efficiently capture and disseminate the lessons learned, and incorporate what was learned into tactics, techniques, and procedures.

\section{Intellectual capital accounting}

According to Roslender and Fincham (2001), intellectual capital is currently the focus of significant discussion and enquiry across the management disciplines and beyond. This reflects the recognition that intellectual capital provides a crucial source of value for the contemporary organization [2].
It is knowledge defined in a particular way, the know-how required to produce process outputs. This kind of knowledge is proportionate to the time it takes to learn it.Learning time has been found to be a quick and convenient way to measure the amount of knowledge contained in any given process. This understanding can be put to test with an example. In a widget company, there is one person,the owner,who makes and sells widgets.

\section{Intellectual capital management}

One of the key authors in the area of intellectual capital is Sveiby (2001), who has developed a knowledge-based theory of the firm to guide in strategy formulation. $\mathrm{He}$ distinguished between three families of intangible assets. The external structure family consists of relationships with customers and suppliers and the reputation of the firm. Some of these relationships can be converted into legal property such as trademarks and brand names. The value of such assets is primarily influenced by how well the company solves its customers problems, and there is always an element of uncertainty here [3].

The internal structure family consists of patents, concepts, models, and computer and administrative systems. These are created by the employees and are thus generally owned by the organization. The structure is partly independent of individuals and some of it remains even if a large number of the employees leave.The individual competence family consists of the competence of the professional staff,the experts, the research and development people,the factory workers, sales and marketing-in short,all those that have a direct contact with customers and whose work is within the business idea.

Competence is a term introduced here. Competence can be defined as the sum of knowledge,skills and abilities at the individual level.With this definition, we say that knowledge is a part of competence, and competence is a part of intellectual 
capital.These three families of intangible resources have slightly different definitions when compared to the capital elements. The external structure seems similar to the relational capital,the internal structure seems similar to structural capital,while the individual competence seems similar to the human capital.

To appreciate why a knowledge-based theory of the organization can be useful for strategy formulation, Sveiby (2001) considers some of the features that differentiate knowledge transfers from tangible goods transfers. In contrast to tangible goods, which tend to depreciate in value when they are used, knowledge grows when used and depreciates when not used. Competence in a language or a sport requires huge investments in training to build up; managerial competence takes a long time on-the-job to learn.If one stops speaking the language it gradually dissipates [4].

\section{Conclusions}

A fundamental idea in the resource based theory is that a firm must continually enhance its resources and capabilities to take advantage of the changing conditions. Optimal growth involves a balance between the exploitation of existing resource positions and the development of new resource positions. This, a firm would be expected to develop new resources after its existing resource base has been fully utilized. Building new resource positions is important if the firm is to achieve sustained growth. When unused productive resources are coupled with changing managerial knowledge,unique opportunities for grow thare created (Pettus, 2001).

According to Johnson and Scholes (2002), successful strategies are dependent on the organization having the strategic capability to perform at the level that is required for success. So the first reason why an understanding of strategic capability is important is concerned with whether an organization's strategies continue to fit the environment in which the organization is operating and the opportunities and threats that exist.Many of the issues of strategy development are concerned with changing the strategic capability so that it fits a changing environment. Understanding strategic capability is also important from another perspective [5]. The organization capability may be the leading edge of strategic developments, in the sense that new opportunities may be created by stretching and exploiting the organization capability either in ways which competitors find difficult to match or in genuinely new directions, or both. This requires organizations to be innovative in the way they develop and exploit their capability.

Organizational knowledge creation involves developing new content or replacing the existing content within the organization's tacit and explicit knowledge. Knowledge is created through social and collaborative processes, as well as through the individual's cognitive processes.

\section{References}

[1] Gooshalk Petter, Strategic Knowledge Management Technology, Idea Group Publishing, Norwegian School of Management, Norway, 2005, pp. 33-37

[2] Department of the Army, Headquarters, Knowledge Management Operations, Washington, DC, 2012, pp. 89-91

[3] Tiwana Amrit, Knowledge Management Toolkit, Prentice Hall, PTR, 1999, pp.51-54

[4] Roceanu Ion, Lungu Ciprian, Managementul cunoștințelor în organizațiile mari, Editura Universității de Apărare Carol I, București, 2013, pp. 115-117

[5] Department of the Army, Headquarters, Knowledge Management Operations, Washington, DC, 2012, pp.103-105 